\title{
Analisis Kelayakan Usahatani Bawang Merah (Allium cepa I.) di Kelurahan Gunung Tabur Kecamatan Gunung Tabur Kabupaten Berau
}

\author{
Indah Puspita Sari ${ }^{1}$, Midiansyah Effendi ${ }^{2}$, Mirza Puspita Widiasari ${ }^{3^{*}}$ \\ 1,3 Sekolah Tinggi Ilmu Pertanian Berau Jl. Raja Alam I Kelurahan Rinding, \\ Kecamatan Teluk Bayur, Kabupaten Berau, Kalimantan Timur, Indonesia. 77311 \\ ${ }^{2}$ Fakultas Pertanian, Universitas Mulawarman \\ ${ }^{3}$ Email: stiperberau.mirza@gmail.com
}

*Penulis korespondensi: stiperberau.mirza@gmail.com

\begin{abstract}
Berau District is one of the food buffer zones prepared for the new capital of the Republic of Indonesia. Shallot Farming in Berau District has been cultivated since 2014 with the widest planting location in Gunung Tabur Subdistrict, so that purposive sampling was use to determine the location. The research aimed to determine the feasibility of shallot farming in Gunung Tabur Village, Gunung Tabur Subdistrict. The Method used in this reasearch was descriptive quantitative method. Determination of sampling used census sampling with 8 respondents. Data collection was done by direct interviews with questionnaires. The results showed that shallot farming is feasible grow. Farming feasibility with an average planting area of 0.23 ha were indicated by value of $R / C$ ratio 2.12 higher than 1 , the value of capital productivity $112 \%$ higher than banking interest, the labor productivity IDR 780,205.00 higher than minimum regional wage, the break event point of Production volume was $38.92 \mathrm{~kg}$, break event point of revenue IDR 1,016,864.00, and break event point of of price was IDR 13,555.00 per $\mathrm{kg}$.
\end{abstract}

Keywords: Break Even Point, Feasibility, Productivity, Revenue, Shallot Farming

\begin{abstract}
ABSTRAK
Kabupaten Berau merupakan salah satu kawasan penyangga pangan yang dipersiapkan untuk Ibu Kota baru Republik Indonesia. Usahatani bawang merah di Kabupaten Berau telah diusahakan sejak tahun 2014 dengan lokasi tanam terluas di Kecamatan Gunung Tabur, sehingga penentuan lokasi dilakukan secara sengaja. Penelitian ini bertujuan untuk mengetahui kelayakan usahatani Bawang Merah di Kelurahan Gunung Tabur Kecamatan Gunung Tabur. Metode yang digunakan dalam penelitian ini adalah metode kuantitatif deskriptif. Penentuan sampel menggunakan sampling jenuh sebanyak 8 responden. Pengumpulan data dilakukan dengan wawancara langsung dengan kuisioner. Hasil penelitian menunjukkan bahwa usahatani bawang merah layak diusahakan. Kelayakan usahatani dengan rata-rata luas tanam 0,23 ha ditunjukkan dengan nilai $\mathrm{R} / \mathrm{C}$ ratio $2,12>1$, produktivitas modal $112 \%>$ suku bunga bank $0,82 \%$, produktivitas tenaga kerja Rp 780.205/HOK>upah minimum kabupaten Rp 156.049,80/HOK, Produksi $1.219 \mathrm{~kg}>$ BEP Produksi 38,92 kg, Penerimaan Rp 35.015.625>BEP Penerimaan Rp 1.016.864, Harga Jual Rp 28.375 / kg>BEP Harga Rp 13.555/kg.
\end{abstract}

Kata kunci: Break Even Point, Kelayakan, Penerimaan, Produktivitas, Usahatani Bawang Merah

\section{Pendahuluan}

Potensi sub sektor hortikultura Indonesia mempunyai peran yang cukup besar dalam pembangunan perekonomian dengan faktor pendukung dasar yaitu kondisi agroklimat dan agroekosistem Indonesia yang sesuai untuk pengembangan produksi 
hortikultura (Kementerian Pertanian, 2015). Pembangunan hortikultura yang meliputi tanaman sayur-sayuran, buah-buahan, tanaman hias dan tanaman obat-obatan diarahkan untuk meningkatkan pendapatan kesejahteraan, taraf hidup serta kemampuan dan kapasitas petani melalui usaha hortikultura dalam sistem agribisnis (Wijayanti, 2001).

Pembangunan pertanian dan hortikultura merupakan bagian yang menyatu dari pembangunan pertanian dalam arti luas yang merupakan salah satu fokus pembangunan di Kalimantan Timur. Kawasan sentra pengembangan hortikultura terpusat di delapan Kabupaten/Kota salah satunya adalah Kabupaten Berau (Humas Provinsi Kalimantan Timur, 2013). Sejalan dengan pengumuman resmi Presiden Republik Indonesia Joko Widodo mengenai pemilihan Provinsi Kalimantan Timur sebagai ibu kota negara Indonesia yang baru pada bulan Agustus 2019, maka Menteri Pertanian menyusun strategi pengembangan kawasan komoditas sebagai penyangga pangan melalui sistem klaster budidaya untuk masing-masing 10 kabupaten di Kalimantan yaitu Kabupaten Berau, Bulungan, Nunukan, Malinau, Tana Bumbu, Tanah Laut, Kapuas Hulu, Ketapang, Kutai Barat dan Paser. Untuk Kabupaten Berau akan dibangun menjadi sentra produksi jagung dan bawang merah (Suara Tani, 2019).

Bawang merah yang tergolong jenis tanaman hortikultura merupakan salah satu komoditas sayuran unggulan yang sejak lama telah diusahakan oleh petani secara intensif, dan termasuk ke dalam kelompok rempah tidak bersubstitusi. Komoditas ini juga merupakan sumber pendapatan dan kesempatan kerja yang memberikan kontribusi cukup tinggi terhadap perkembangan ekonomi wilayah (Rahayu \& Berlian, 2004; Badan Penelitian dan Pengembangan Pertanian Departemen Pertanian, 2005). Peraturan Presiden Republik Indonesia Nomor 71 Tahun 2015 menetapkan Bawang Merah sebagai salah satu barang kebutuhan pokok hasil pertanian. Bawang merah merupakan tanaman semusim yang memiliki fungsi utama sebagai bumbu penyedap masakan khususnya di Asia Tenggara dan negara lain dengan bagian yang paling banyak dimanfaatkan adalah umbi. Secara umum bawang merah lebih banyak dipasarkan dalam bentuk segar. Sebagian masyarakat mengenal olahan bawang merah sebatas untuk bawang goreng atau campuran acar. Walaupun produk olahan bawang merah berupa pasta dan minyak bawang merah saat ini belum populer, namun prospeknya cukup menjanjikan. Pergeseran pola konsumsi masyarakat yang serba praktis dan instan dalam memasak sehingga produk olahan bawang merah semakin diminati. Oleh karenanya, permintaan sebagai bahan baku maupun sebagai bahan tambahan terus meningkat pada industri makanan. Kandungan zat antibiotik didalamnya menjadikan bawang merah bermanfaat sebagai obat tradisional, dan kandungan bahan kimia lainnya seperti minyak atsiri, sikloaliin, metilaliin, dihidroaliin, flavonglikosida, saponin, peptida, fitohormon, dan kuersetin juga menjadikan bawang merah sebagai salah satu bahan pengembangan Jpt. Jurnal Pertanian Terpadu, Jilid 9, Nomor $1 \mid 14$ 
ISSN 2354-7251 (print)

pembuatan pestisida nabati (Direktorat Barang Kebutuhan Pokok dan Barang Penting

Kementerian Perdagangan RI, 2013; Sudarmo \& Mulyaningsih, 2014; Balai Penelitian Tanaman Sayuran, 2019; Manurung, 2019).

Berdasarkan data Badan Pusat Statistik dan Direktorat Jenderal Hortikultura (2019) bahwa tahun 2018 untuk lingkup Pulau Kalimantan, produksi bawang merah Kalimantan Timur sebesar 828 ton merupakan terbesar kedua setelah Kalimantan Selatan 1.412 ton. Walaupun pada tahun 2018 produktivitas bawang merah Kalimantan Timur turun $23,18 \%$ dibandingkan tahun 2017. Namun, Kalimantan Timur tetap yang tertinggi yaitu 5,56 ton $\mathrm{ha}^{-1}$, setelah itu urutan kedua tidak jauh berbeda adalah Kalimantan Selatan 5,25 ton ha ${ }^{-1}$. Luas panen dan produksi bawang merah di Kalimantan Timur dari tahun 2015-2018 terus meningkat setiap tahun. Pada tahun 2018 luas panen terbesar berada di Kabupaten Berau yaitu 54 ha naik 14,89\% dibandingkan tahun 2017. Meskipun terjadi penurunan produktivitas $43,53 \%$ atau menjadi 4,8 ton ha $^{-1}$ yang mengakibatkan jumlah produksi juga turun $35,16 \%$ atau 140,5 ton. Hal ini tidak mempengaruhi kedudukan Kabupaten Berau sebagai penghasil terbesar bawang merah di Kalimantan Timur (Badan Pusat Statistik Provinsi Kalimantan Timur, 2019).

Pada tahun 2018 ada enam kecamatan yang mengembangkan usahatani bawang merah di Kabupaten Berau yaitu Kecamatan Talisayan, Sambaliung, Gunung Tabur, Teluk Bayur, Batu Putih dan Biatan. Kecamatan Gunung Tabur merupakan daerah yang terluas untuk pengembangan bawang merah dengan luas panen 53,5 ha dan produksi 228,6 ton (BPS Kabupaten Berau, 2019 dan Dinas Pertanian dan Peternakan, 2019). Fokus kegiatan pengembangan bawang merah di Kecamatan Gunung Tabur yang terluas berada di Kelurahan Gunung Tabur yaitu Kelompok Tani Sumber Tani Jaya. Sejak 2014 usahatani bawang merah mulai dikembangkan di Kabupaten Berau dan Kecamatan Gunung Tabur merupakan daerah pertama dengan luas panen 5 ha dan produktivitas 9,8 ton ha ${ }^{-1}$ menggunakan bibit varietas katumi (BPP Kecamatan Gunung Tabur, 2019).

Usahatani bawang merah di lokasi penelitian tergolong usahatani keluarga yang berorientasi pada pendapatan, sehingga upaya peningkatan kualitas serta kuantitas produk terus dilakukan agar dapat memenuhi permintaan pasar. (Suratiyah, 2015) juga memaparkan bahwa bentuk usahatani keluarga umumnya berlahan sempit, namun tetap dengan tujuan akhir untuk pendapatan keluarga petani. Rata-rata luas lahan yang dimiliki petani bawang merah di Kelurahan Gunung Tabur adalah 2 ha dengan luas tanam ratarata hanya 0,23 ha, keterbatasan penyediaan bibit umbi bawang merah dari luar Kalimantan dan kurangnya tenaga kerja menjadi salah satu penyebabnya. Namun demikian dalam pengelolaan usahataninya, mereka terus berupaya untuk meningkatkan pengetahuan dalam penggunaan faktor-faktor produksi berdasarkan pengalaman selama 5 tahun membudidayakan bawang merah serta pemanfaatan informasi teknologi dari PPL Jpt. Jurnal Pertanian Terpadu, Jilid 9, Nomor 1| 15 
setempat, karenanya usahatani ini mempunyai peluang mengarah pada pertanian modern sesuai ciri yang diutarakan (Andianto, 2014) yaitu pertanian yang dilakukan di lahan menetap yang keberhasilannya tergantung pada kemampuan manusia dalam mengatur dan mengendalikan pertumbuhan tanaman, serta segala permasalahan yang dihadapi dipecahkan secara alamiah dan ilmiah.

Ditinjau dari prospek pasar usahatani bawang merah di Kelurahan Gunung Tabur cukup baik dengan harga jual rata-rata produksi umbi kering kotor bawang merah antara Rp 21.000 sampai Rp 31.000 per $\mathrm{kg}$. Secara garis besar harga yang diterima petani cukup tinggi, tetapi belum diketahui secara rinci pengeluaran atau biaya-biaya penggunaan faktor-faktor produksinya. Saat ini petani umumnya sudah mengadakan perhitungan ekonomi, hanya saja tidak semua dilakukan secara tertulis dan masih banyak petani yang belum menghitung secara rinci berapa tingkat pendapatan usahataninya sedangkan hal ini merupakan informasi dasar untuk mengetahui kelayakan usahatani bawang merah yang dikembangkan. Berdasarkan permasalahan di atas maka penelitian ini bertujuan untuk mengetahui kelayakan usahatani bawang merah di Kelurahan Gunung Tabur.

\section{Metode Penelitian}

\section{Waktu dan Tempat Penelitian}

Penelitian dilaksanakan selama 3 bulan yaitu dari bulan November 2019-Januari 2020. Pemilihan lokasi penelitian dilakukan secara sengaja (purposive) di Kelurahan Gunung Tabur Kecamatan Gunung Tabur Kabupaten Berau karena merupakan daerah pertama pengembangan dan terluas, serta petani yang berpengalaman.

\section{Metode Pengumpulan Data}

Data yang digunakan dalam penelitian ini adalah data primer dan data sekunder. Data primer adalah data yang diperoleh melalui pengamatan dan wawancara secara langsung dengan responden menggunakan daftar pertanyaan (Kuisioner) yang sudah disusun sesuai dengan tujuan penelitian, sedangkan data sekunder adalah data yang diperoleh melalui data-data dari beberapa literatur dan instansi yang terkait, seperti Dinas Pertanian dan Peternakan Kabupaten Berau, kantor kecamatan dan kelurahan, Badan Pusat Statistik Kabupaten Berau, serta sumber informasi lain yang mendukung penelitian ini.

\section{Metode Pengumpulan Sampel}

Data dari Balai Penyuluh Pertanian Kecamatan Gunung Tabur (2019), jumlah kelompok tani yang mengusahakan bawang merah di Kelurahan Gunung Tabur yaitu satu kelompok bernama Sumber Tani Jaya dengan jumlah awal anggotanya 23 orang berkurang menjadi 8 orang saja yang aktif, sehingga metode yang digunakan untuk Jpt. Jurnal Pertanian Terpadu, Jilid 9, Nomor $1 \mid 16$ 
ISSN 2354-7251 (print)

pengambilan sampel yaitu metode sampling jenuh (sensus). Hal ini dilakukan jika jumlah anggota populasi relatif kecil ( $<30$ orang) atau penelitian yang ingin membuat generalisasi dengan kesalahan sangat kecil (Sugiyono, 2016).

\section{Metode Analisis Data}

1. Biaya Produksi, Penerimaan, Pendapatan dan Keuntungan

Rumus biaya produksi:

$$
\mathrm{TC}=\mathrm{TFC}+\mathrm{TVC}
$$

Keterangan: $\mathrm{TC}=$ Total Cost (Total Biaya)

TFC $=$ Total Fixed Cost (Total Biaya Tetap)

TVC $=$ Total Variable Cost (Total Biaya Variabel)

Besarnya penerimaan (revenue) dihitung dengan rumus:

$$
\mathrm{TR}=\mathrm{Q} \times \mathrm{P}
$$

Keterangan: $\mathrm{TR}=$ Total Revenue (Total Penerimaan)

$\mathrm{Q} \quad=$ Jumlah Produksi

$\mathrm{P} \quad=$ Harga Jual Hasil Produksi

Pendapatan usahatani adalah selisih antara penerimaan dan biaya eksplisit. Setelah diperoleh penerimaan dan total biaya eksplisit, maka pendapatan dapat dilihat dengan rumus (Suratiyah, 2015):

$$
\mathrm{NR}=\mathrm{TR}-\mathrm{TEC}
$$

$$
\begin{aligned}
\text { Keterangan: } \mathrm{NR} & =\text { Net Return }(\text { Pendapatan) } \\
\mathrm{TR} & =\text { Total Revenue }(\text { Total Penerimaan }) \\
\mathrm{TEC} & =\text { Total Explicit Cost }(\text { Total Biaya Eksplisit })
\end{aligned}
$$

Keuntungan adalah selisih antara penerimaan dengan jumlah total yang benar-benar nyata dikeluarkan untuk mendukung proses produksi. Secara matematis keuntungan dapat dirumuskan sebagai berikut (Sukirno, 2016):

$$
\pi=\mathrm{TR}-\mathrm{TIC}
$$

Keterangan: $\Pi \quad=$ Keuntungan

$$
\begin{aligned}
\mathrm{TR} & =\text { Total Revenue (Total Penerimaan) } \\
\mathrm{TIC} & =\text { Total Implisit Cost (Total biaya Implisit) }
\end{aligned}
$$

\section{Analisis Kelayakan Usaha}

Kelayakan usahatani dapat diukur dari 6 aspek, yaitu perbandingan penerimaan dengan biaya $(R / C$ ratio), produktivitas modal $(\pi / C)$, produktivitas tenaga kerja (PTK), BEP produksi, BEP penerimaan dan BEP harga. Usahatani dikatakan layak jika nilai R/C $>1, \pi / \mathrm{C}>$ bunga bank yang berlaku, PTK > Upah Minimum Kabupaten (UMK), produksi > BEP produksi, penerimaan > BEP penerimaan dan harga > BEP harga. 


\section{Hasil dan Pembahasan}

\section{Analisis Biaya}

Biaya usahatani bawang merah yang dihitung dalam penelitian ini meliputi biaya tetap dan biaya variabel serta biaya implisit dan biaya eksplisit. Biaya tetap meliputi penyusutan alat dan biaya variabel meliputi biaya benih atau bibit, pupuk, pestisida, tenaga kerja, dan biaya lain-lain (bahan bakar minyak), sedangkan biaya implisit meliputi tenaga kerja dalam keluarga, dan biaya eksplisit meliputi tenaga kerja luar keluarga, sarana produksi, dan biaya lain-lain.

Tabel 1. Rincian biaya 8 petani bawang merah di Kelurahan Gunung Tabur dengan luas tanam

\begin{tabular}{|c|c|c|c|}
\hline No & Jenis Biaya & $\begin{array}{c}\text { Jumlah Biaya } \\
\left({\left.\text { Rp } \mathrm{mt}^{-1}\right)}^{-}\right.\end{array}$ & $\begin{array}{l}\text { Rata-rata } \\
\left(\text { Rp mt }^{-1}\right)\end{array}$ \\
\hline \multirow[t]{3}{*}{1} & Biaya Tetap & & \\
\hline & Penyusutan Alat & $4.392 .857,00$ & $549.107,00$ \\
\hline & Total Biaya Tetap & 4.392.857,00 & $549.107,00$ \\
\hline \multirow[t]{7}{*}{2} & Biaya Variabel & & \\
\hline & Bibit (Umbi) & $57.750 .000,00$ & 7.218.750,00 \\
\hline & Pupuk & $12.330 .000,00$ & $1.541 .250,00$ \\
\hline & Pestisida & $14.202 .000,00$ & $1.775 .250,00$ \\
\hline & Tenaga Kerja & $43.080 .000,00$ & $5.385 .000,00$ \\
\hline & Bahan Bakar Minyak & $435.000,00$ & $435.000,00$ \\
\hline & Total Biaya Variabel & $127.797 .000,00$ & $15.974 .625,00$ \\
\hline \multirow[t]{8}{*}{3} & Biaya Eksplisit & & \\
\hline & Bibit (Umbi) & $57.750 .000,00$ & $7.218 .750,00$ \\
\hline & Pupuk & $12.330 .000,00$ & $1.541 .250,00$ \\
\hline & Pestisida & $14.202 .000,00$ & $1.775 .250,00$ \\
\hline & Tenaga Kerja Luar Keluarga & $12.000 .000,00$ & $12.000 .000,00$ \\
\hline & Bahan Bakar Minyak & $435.000,00$ & $435.000,00$ \\
\hline & Penyusutan Alat & 4.392.857,00 & $549.107,00$ \\
\hline & Total Biaya Eksplisit & $101.109 .857,00$ & $12.638 .732,00$ \\
\hline \multirow[t]{3}{*}{4} & Biaya Implisit & & \\
\hline & Biaya Tenaga Kerja Dalam Keluarga & $31.080 .000,00$ & $3.885 .000,00$ \\
\hline & Total Biaya Implisit & $31.080 .000,00$ & $3.885 .000,00$ \\
\hline \multicolumn{2}{|c|}{ Jumlah Biaya Tetap dan Biaya Variabel } & $132.189 .857,00$ & $16.523 .732,00$ \\
\hline \multicolumn{2}{|c|}{ Jumlah Biaya Eksplisit dan Biaya Implisit } & $132.189 .857,00$ & $16.523 .732,00$ \\
\hline
\end{tabular}

Sumber: Data primer diolah (2020)

Tabel 1 menunjukkan bahwa jumlah biaya tetap sebesar Rp 4.392 .857 yaitu biaya penyusutan alat. Biaya variabel menunjukkan biaya bibit sebesar Rp 57.750.000, pupuk sebesar Rp 12.330.000, pestisida sebesar Rp 14.202.000, tenaga kerja sebesar $R p$ 43.080.000, dan biaya bahan bakar minyak sebesar Rp 435.000. Pengeluaran terbesar ada pada biaya bibit. Hal ini dikarenakan bibit (umbi) yang digunakan merupakan varietas Katumi dengan harga Rp 35.000 per kg dengan rata-rata kebutuhan satu musim tanam $206 \mathrm{~kg}$. Bibit tersebut tidak tersedia di toko-toko pertanian ataupun penangkar benih di Kabupaten Berau, sehingga penyediaannya harus dikirim dari luar daerah (Pulau Jawa).

Pada biaya implisit dan eksplisit terjadi pemisahan perhitungan antara tenaga kerja luar dan tenaga kerja dalam keluarga sehingga total biaya implisit sebesar $\mathrm{Rp}$ 31.080.000 yaitu biaya tenaga kerja dalam keluarga, dan total biaya eksplisit sebesar Rp 101.109.857. Biaya tenaga kerja dalam keluarga termasuk kedalam biaya implisit karena Jpt. Jurnal Pertanian Terpadu, Jilid 9, Nomor $1 \mid 18$ 
ISSN 2354-7251 (print)

seringkali tidak dikeluarkan secara langsung. Tenaga kerja dalam keluarga pada umumnya oleh para petani tidak diperhitungkan dan penggunaannya tergantung dari jumlah anggota keluarga dewasa dan jenis kelamin (pria). Semua total biaya baik penjumlahan biaya tetap dan biaya variabel maupun penjumlahan biaya implisit dan eksplisit menghasilkan total biaya sama yaitu sebesar Rp 132.189.857.

\section{Analisis Penerimaan, Pendapatan dan Keuntungan}

Produksi merupakan hasil akhir dari sebuah proses produksi dalam usahatani. Jumlah produksi akan menentukan jumlah penerimaan dari usahatani. Rata-rata jumlah produksi petani di Kelurahan Gunung Tabur sebesar $1.219 \mathrm{~kg} \mathrm{mt}^{-1}$ atau $5.775 \mathrm{~kg} \mathrm{ha}^{-1}$. Randi (2018) menyatakan bahwa faktor yang berpengaruh dominan terhadap produksi bawang merah di Kecamatan Gunung Tabur adalah bibit. Bibit umbi yang digunakan petani adalah varietas Katumi dan Bima Brebes. Menurut pengalaman petani di lokasi penelitian menyatakan bahwa pemilihan varietas ini sangat menentukan kualitas dan kuantitas produksi. Bibit Katumi dianggap yang paling sesuai dengan kondisi lahan karena lebih subur, tidak mudah busuk dan tahan lama serta produksi sesuai dengan harapan petani. Hal ini sejalan dengan penelitian (Purba, 2014) di Kabupaten Serang, Banten bahwa penggunaan varietas Katumi di luar musim dapat memberikan produksi yang lebih baik dibandingkan dengan varietas Manjoung, Bima dan Bima Curut (lokal). Kemudian diperkuat oleh (Kartinaty et al., 2019) menunjukkan varietas bima dan katumi menghasilkan produksi tertinggi yaitu 9,37 ton ha-1 dan 9,09 ton ha-1, sehingga dua varietas ini direkomendasikan untuk dikembangkan di Kalimantan Barat. Penerimaan dihitung dengan mengalikan jumlah produksi bawang merah dengan harga jual produk. Hasil penelitian menunjukkan bahwa harga jual rata-rata sebesar $\mathrm{Rp} 28.375$ per kg, sehingga penerimaan rata-rata satu musim tanam adalah $\mathrm{Rp} 35.015 .625$ dapat dilihat pada Tabel 2.

Tabel 2. Rata-rata penerimaan dan pendapatan 8 petani bawang merah di Kelurahan Gunung Tabur dengan luas tanam rata-rata 0,23 ha

\begin{tabular}{clc}
\hline No & & Nilai (Rp t $\left.^{-1}\right)$ \\
\hline 1 & Produksi & \\
2 & $-1.219 \mathrm{~kg} \mathrm{mt}^{-1}$ & \\
& Harga & \\
3 & - Rp 28.375 & 35.015 .625 \\
4 & Penerimaan & 12.638 .732 \\
5 & Biaya Eksplisit & 3.885 .000 \\
6 & Biaya Implisit & 22.376 .893 \\
7 & Kendapatan (3-4) & 18.491 .893
\end{tabular}

Sumber: Data primer diolah (2020)

Keuntungan merupakan selisih antara pendapatan dengan biaya implisit, sedangkan pendapatan adalah penerimaan dikurangi dengan biaya eksplisit. Berdasarkan Tabel 2 diketahui bahwa selama satu musim tanam bawang merah petani 
akan mendapatkan rata-rata pendapatan $\mathrm{Rp} 22.376 .893$ dan rata-rata keuntungan $\mathrm{Rp}$ 18.491.893.

\section{Analisis Break Even Point (BEP)}

Break Even Point (BEP) merupakan titik impas bagi petani agar memperoleh keuntungan. Apabila usahatani yang dikelola berada di bawah titik impas maka artinya rugi, dan begitu juga sebaliknya. Rata-rata BEP usahatani bawang merah di Kelurahan Gunung Tabur dapat dilihat pada Tabel 3.

Tabel 3. Rata-rata BEP 8 petani bawang merah di Kelurahan Gunung Tabur dengan luas tanam rata-rata 0,23 ha

\begin{tabular}{|c|c|c|}
\hline No & Uraian & Nilai \\
\hline 1 & Total Produksi $(Y)$ & $1.219 \mathrm{~kg}$ \\
\hline 2 & Total Biaya (TC) & Rp16.523.732 \\
\hline 3 & Biaya Tetap (TFC) & Rp549.107 \\
\hline 4 & Biaya Variabel (TVC) & Rp15.974.625 \\
\hline 5 & Biaya Variabel per Unit (AVC) & Rp14.267 \\
\hline 6 & Harga Produk $(\mathrm{P})$ & Rp28.375 kg-1 \\
\hline 7 & BEP Produksi & $38,92 \mathrm{~kg}$ \\
\hline 8 & BEP Penerimaan & Rp1.016.864 \\
\hline 9 & BEP Harga & Rp13.555 \\
\hline
\end{tabular}

Sumber: Data primer diolah (2020)

Tabel 3 menunjukkan bahwa petani tidak akan memperoleh keuntungan ataupun menderita kerugian bila menghasilkan bawang merah dalam satu musim tanam sebanyak $38,92 \mathrm{~kg}$ dengan harga jual $\mathrm{Rp} 13.555$ dan penerimaan sebesar $\mathrm{Rp}$ 1.016.864.

\section{Analisis Kelayakan}

Kelayakan usahatani bawang merah di Kelurahan Gunung Tabur diukur dengan 6 aspek yaitu Perbandingan penerimaan dengan biaya ( $R / C$ Ratio), produktivitas modal $(\pi / C)$, dan produktivitas tenaga kerja (PTK). Usahatani dikatakan layak jika nilai $R / C>1$, $\pi / C>$ bunga bank yang berlaku, PTK > Upah Minimum Kabupaten (UMK), total produksi $>$ BEP Produksi, penerimaan > BEP penerimaan dan harga produksi > BEP harga.

\section{R/C Ratio}

Analisis $R / C$ Ratio dihitung dengan membandingkan antara penerimaan dengan biaya. Analisis R/C Ratio merupakan salah satu cara untuk mengetahui kelayakan suatu usaha. Rata-rata $R / C$ ratio usahatani bawang merah di Kelurahan Gunung Tabur dapat dilihat di Tabel 4.

Tabel 4. Rata-rata $R / C$ Ratio 8 petani bawang merah di Kelurahan Gunung Tabur

\begin{tabular}{clc}
\hline No & \multicolumn{1}{c}{ Uraian } & Nilai \\
\hline 1 & Penerimaan $(\mathrm{R})$ & $\mathrm{Rp} \mathrm{35.015.625}$ \\
2 & Total Biaya $(\mathrm{C})$ & $\mathrm{Rp} 16.523 .732$ \\
3 & $R / C$ Ratio & 2,12 \\
\hline
\end{tabular}

Sumber: Data primer diolah (2020)

Berdasarkan Tabel 4 diketahui bahwa $R / C$ Ratio $>1$. Hal ini menunjukan bahwa setiap pengeluaran biaya $\mathrm{Rp} 1.000$ maka akan diperoleh penerimaan $\mathrm{Rp} 2.120$ artinya bahwa usahatani bawang merah di Kelurahan Gunung Tabur layak diusahakan. Hal ini sejalan dengan penelitian (Purba, 2014) yang juga meneliti varietas Katumi menunjukkan Jpt. Jurnal Pertanian Terpadu, Jilid 9, Nomor $1 \mid 20$ 
ISSN 2354-7251 (print)

nilai $R / C$ Ratio 2,24 walaupun ditanam diluar musim. Penelitian lain di Kecamatan Rasau Jaya Kabupaten Kubu Raya juga menunjukkan nilai R/C Ratio 1,95 (Sugianto et al., 2019). Penelitian usahatani bawang merah di Kecamatan Gunung Tabur juga pernah dilakukan oleh Syuwaib (2018) menunjukkan nilai R/C Ratio 1,48 menggunakan bibit varietas Bima Brebes.

Tabel 5. Distribusi 8 petani bawang merah menurut $R / C$ Ratio di Kelurahan Gunung Tabur

\begin{tabular}{rccc}
\hline No. & $\boldsymbol{R}$ (C Ratio & Jumlah Petani (Orang) & Presentase (\%) \\
\hline 1 & $\leq 1$ & 2 & 25 \\
2 & $>1$ & 6 & 75 \\
\hline & Jumlah & 8 & 100
\end{tabular}

Sumber: Data primer diolah (2020)

Tabel 5 menunjukkan bahwa ada enam petani dengan nilai $R / C$ Ratio lebih dari satu $(75 \%)$ dan nilai $R / C$ Ratio kurang dari satu ada dua petani $(25 \%)$. Hal ini disebabkan pada musim tanam terakhir terjadi gagal panen akibat bawang merah terserang penyakit dengan jumlah produksi hanya $375 \mathrm{~kg}$ pada luas tanam $0,13 \mathrm{ha}$, dengan perbandingan rata-rata produksi di lokasi penelitian dapat mencapai $5.775 \mathrm{~kg} \mathrm{ha}^{-1}$.

2. Produktivitas Modal

Produktivitas modal dihitung dengan membandingkan keuntungan yang diperoleh dengan total biaya yang dikeluarkan. Rata-rata produktivitas modal usahatani bawang merah di Kelurahan Gunung Tabur dapat dilihat di Tabel 6.

Tabel 6. Rata-rata produktivitas modal 8 petani bawang merah di Kelurahan Gunung Tabur

\begin{tabular}{clc}
\hline No & \multicolumn{1}{c}{ Uraian } & Nilai \\
\hline 1 & Keuntungan $(\pi)$ & Rp 18.491.893 \\
2 & Total Biaya $(\mathrm{C})$ & $\mathrm{Rp} 16.523 .732$ \\
3 & $\pi / C$ ratio & 1,12 \\
\hline
\end{tabular}

Sumber: Data primer diolah (2020)

Berdasarkan Tabel 6 diketahui bahwa produktivitas modal dalam berusahatani bawang merah sebesar 1,12 atau $112 \%$. Hasil perhitungan menunjukan bahwa dengan mengeluarkan modal Rp 1.000 maka diperoleh keuntungan sebesar Rp 1.120. Suatu usaha akan dikatakan layak bila produktivitas modal lebih besar daripada besarnya suku bunga bank. Suku bunga bank BRI yang digunakan sebagai tolak ukur yaitu 0,82\%, artinya usahatani Bawang Merah di Kelurahan Gunung Tabur layak diusahakan. Penelitian serupa di Kecamatan Rasau Jaya Kabupaten Kubu Raya juga menunjukkan nilai $\pi / C$ ratio memiliki nilai rata-rata $89 \%$ lebih besar jika dibandingkan dengan bunga KUR tahun 2017 yaitu 7\% (Sugianto et al., 2019).

Tabel 7. Distribusi 8 petani bawang merah menurut produktivitas modal di Kelurahan Gunung Tabur

\begin{tabular}{lccc}
\hline No. & Produktivitas Modal (Rp) & Jumlah Petani (Orang) & Presentase (\%) \\
\hline 1 & $\leq$ Bunga Bank & 2 & 25 \\
2 & > Bunga Bank & 6 & 75 \\
\hline & Jumlah & 8 & 100
\end{tabular}

Sumber: Data primer diolah (2020) 
Berdasarkan Tabel 7 diketahui bahwa $25 \%$ produktivitas modal lebih kecil dari bunga bank dan $75 \%$ memiliki produktivitas modal lebih besar dari bunga bank. Petani dengan produktivitas modal lebih kecil dari bunga bank artinya usahatani bawang merah yang diusahakannya tidak layak sehingga mengakibatkan modal petani yang berasal dari pinjaman bank tidak dapat dikembalikan.

3. Produktivitas Tenaga Kerja

Produktivitas tenaga kerja dihitung dengan membandingkan antara penerimaan yang diperoleh dengan banyaknya tenaga kerja yang digunakan dalam usahatani bawang merah. Rata-rata produktivitas tenaga kerja usahatani bawang merah di Kelurahan Gunung Tabur dapat dilihat di Tabel 8.

Tabel 8. Rata-rata produktivitas tenaga kerja 8 petani bawang merah di Kelurahan Gunung Tabur

\begin{tabular}{|c|c|c|}
\hline No & Uraian & Nilai \\
\hline 1 & Penerimaan (R) & Rp 35.015.625 \\
\hline 2 & Total Tenaga Kerja & $44,88 \mathrm{HOK}$ \\
\hline 3 & $\mathrm{R} /$ Total tenaga kerja & Rp $780.205 \mathrm{HOK}^{-1}$ \\
\hline
\end{tabular}

Sumber: Data primer diolah (2020)

Berdasarkan Tabel 8 diketahui bahwa rata-rata produktivitas tenaga kerja pada usahatani bawang merah sebesar Rp780.205 per HOK, artinya bahwa setiap curahan satu hari tenaga kerja mampu menghasilkan nilai jual produk bawang merah sebesar Rp 780.205. Suatu usahatani dikatakan layak apabila produktivitas tenaga kerja lebih besar dari Upah Minimum Kabupaten (UMK). Besarnya UMK Berau adalah Rp 156.050 per HOK. Dengan demikian usahatani bawang merah di Kelurahan Gunung Tabur termasuk layak diusahakan.

Tabel 9. Distribusi 8 petani bawang merah menurut produktivitas tenaga kerja di Kelurahan Gunung Tabur

\begin{tabular}{|c|c|c|c|}
\hline No & Produktivitas Tenaga Kerja (Rp) & Jumlah Petani (Orang) & Presentase (\%) \\
\hline 1 & $\leq$ UMK & 0 & 0 \\
\hline 2 & > UMK & 8 & 100,00 \\
\hline & Jumlah & 8 & 100,00 \\
\hline
\end{tabular}

Sumber: Data primer diolah (2020)

Tabel 9 menunjukkan bahwa seluruh petani bawang merah di Kelurahan Gunung Tabur memiliki produktivitas tenaga kerja lebih besar dari upah minimum kabupaten, artinya usahatani bawang merah yang diusahakan layak. Penerimaan yang diperoleh petani sebanding dengan curahan tenaga kerja yang telah digunakan. 
4. Break Even Point (BEP) Produksi

BEP produksi digunakan untuk mengetahui pada jumlah produksi berapakah penjualan yang diperoleh sama dengan besarnya biaya yang dikeluarkan, sehingga petani tidak untung dan tidak rugi.

Tabel 10. Distribusi 8 petani bawang merah menurut BEP produksi di Kelurahan Gunung Tabur

\begin{tabular}{clcc}
\hline No & BEP Produksi $(\mathbf{k g})$ & Jumlah Petani (Orang) & Presentase (\%) \\
\hline 1 & $\leq$ BEP produksi & 0 & 0 \\
2 & $>$ BEP produksi & 8 & 100 \\
\hline & Jumlah & 8 & 100
\end{tabular}

Sumber: Data primer diolah (2020)

Berdasarkan Tabel 10 menunjukkan bahwa 100\% petani bawang merah di Kelurahan Gunung Tabur menjual bawang merah dengan jumlah di atas BEP Produksi, artinya usahatani untung dan layak diusahakan.

\section{Break Even Point (BEP) Penerimaan}

BEP penerimaan digunakan untuk mengetahui pada berapakah penjualan yang diperoleh agar sama dengan besarnya biaya yang dikeluarkan sehingga petani tidak untung dan tidak rugi.

Tabel 11. Distribusi 8 petani bawang merah menurut BEP penerimaan di Kelurahan Gunung Tabur

\begin{tabular}{cccc}
\hline No & BEP Penerimaan (Rp) & Jumlah Petani (Orang) & Presentase (\%) \\
\hline 1 & $\leq$ BEP penerimaan & 0 & 0 \\
2 & > BEP penerimaan & 8 & 100,00 \\
\hline & Jumlah & 8 & 100,00
\end{tabular}

Sumber: Data primer diolah (2020)

Berdasarkan Tabel 11 menunjukkan bahwa seluruh petani bawang merah di Kelurahan Gunung Tabur memperoleh penerimaan diatas BEP penerimaan, artinya usahatani bawang merah yang diusahakan untung dan layak.

6. Break Even Point (BEP) Harga

BEP harga merupakan perbandingan antara total biaya dengan total produksi. BEP harga digunakan untuk mengetahui pada harga berapakah penjualan yang diperoleh sama dengan besarnya biaya yang dikeluarkan sehingga petani tidak untung tidak rugi.

Tabel 12. Distribusi 8 petani bawang merah menurut BEP harga di Kelurahan Gunung Tabur

\begin{tabular}{cccc}
\hline No & BEP Harga (Rp) & Jumlah Petani (Orang) & Presentase (\%) \\
\hline 1 & $\leq$ BEP Harga & 0 & 0 \\
2 & > BEP Harga & 8 & 100 \\
\hline & Jumlah & 8 & 100
\end{tabular}

Sumber : Data Primer diolah (2020)

Berdasarkan Tabel 12 menunjukkan bahwa seluruh petani bawang merah di Kelurahan Gunung Tabur menjual bawang merah dengan harga di atas BEP harga, artinya usahatani untung dan layak diusahakan. 


\section{Kesimpulan}

Usahatani bawang merah di Kelurahan Gunung Tabur Kecamatan Gunung Tabur dari keseluruhan analisis data dapat disimpulkan bahwa usahatani ini layak dikembangkan. Rata-rata $R / C$ Ratio sebesar 2,12 lebih besar dari 1. Rata-rata produktivitas Modal sebesar 1,12 atau 112\% lebih besar dari tingkat suku bunga Bank Rakyat Indonesia (BRI) per dua bulan. Rata-rata produktivitas tenaga kerja sebesar Rp 780.205 per HOK lebih besar dari Upah Minimum Kabupaten tahun 2019 per HOK. Ratarata 8 responden dapat menjual produksi bawang merah dengan harga diatas nilai BEP produksi dan BEP harga, sehingga penerimaan yang diperoleh lebih dari BEP penerimaan.

\section{Daftar Pustaka}

Andianto, T. T. (2014). Pengantar Ilmu Pertanian (Agraris, Agrobisnis, Agroindustri, dan Agroteknologi). Yogyakarta: Global Pustaka Utama.

Badan Penelitian dan Pengembangan Pertanian Departemen Pertanian. (2005). Prospek dan Arah Pengembangan Agribisnis Bawang Merah. https://www.litbang.pertanian.go.id

Badan Pusat Statistik dan Direktorat Jenderal Hortikultura. (2019). Produksi Bawang Merah Menurut Provinsi, Tahun 2014-2018. https://hortikultura.pertanian.go.id

Badan Pusat Statistik Provinsi Kalimantan Timur. (2019). Kalimantan Timur Dalam Angka. Samarinda: BPS Provinsi Kalimantan Timur.

Badan Pusat Statistik Kabupaten Berau. (2019). Kabupaten Berau Dalam Angka. Tanjung Redeb: BPS Kabupaten Berau.

Balai Penelitian Tanaman Sayuran (Balitsa) Puslitbang Hortikultura Baplitbang Pertanian Kementerian Pertanian. (2019). Ragam Produk Olahan Bawang Merah dan Prospek Usaha. https://balitsa.litbang.pertanian.go.id

Balai Penyuluh Pertanian (BPP) Kecamatan Gunung Tabur. (2019). Data Kelompok Tani dan Komoditas Pertanian Kecamatan Gunung Tabur. Gunung Tabur: BPP Gunung Tabur.

Dinas Pertanian dan Peternakan. (2019). Data Statistik Pertanian (SP) Luas Tanam, Luas Panen, Produksi Bawang Merah per Kecamatan Kabupaten Berau (Angka Tetap). Tanjung Redeb: Dinas Pertanian dan Peternakan Kabupaten Berau.

Direktorat Barang Kebutuhan Pokok dan Barang Penting Kementerian Perdagangan RI. (2013). Profil Komoditas Bawang Merah. https://ews.kemendag.go.id

Humas Provinsi Kalimantan Timur. (2013). Pertanian dan Hortikultura Fokus Pembangunan Kaltim. https://kaltimprov.go.id

Kartinaty, T., Hartono, H., \& Serom, S. (2019). Penampilan Pertumbuhan Dan Produksi Lima Varietas Bawang Merah (Allium ascalonicum) di Kalimantan Barat. BUANA SAINS, 18(2), 103-108. 
ISSN 2354-7251 (print)

Kementerian Pertanian. (2015). Renstra Direktorat Jenderal Hortikultura 2015-2019. http://hortikultura.pertanian.go.id

Manurung, M. (2019). Konsumsi dan Neraca Penyediaan-Penggunaan Bawang Merah. Buletin Konsumsi Pangan, 10(1), 56-62.

Purba, R. (2014). Produksi dan Keuntungan Usahatani Empat Varietas Bawang Merah di Luar Musim (Off-season) Dikabupaten Serang, Banten. Agriekonomika, 3(1), 55-64.

Rahayu, E., \& Berlian, N. V. A. (2004). Bawang Merah. Jakarta: Penebar Swadaya.

Randi. (2018). Pengaruh Faktor Produksi Terhadap Usaha Tani Bawang Merah Bawang Merah (Allium ascolanicum, L.) di Kampung Maluang Kecamatan Gunung Tabur, Skripsi, STIPER Berau, Teluk Bayur.

Suara Tani. (2019). 10 Kabupaten Ini Jadi Penyangga Pangan Kaltim, Berau Sentra Jagung dan Bawang Merah. https://suratani.com/news.

Sudarmo, S., \& Mulyaningsih, S. (2014). Mudah Membuat Pestisida Nabati Ampuh. AgroMedia.

Sugianto, S., Kurniawan, H. M., \& Yuliarto, R. T. (2019). Analisis Kelayakan Usahatani Bawang Merah Di Kecamatan Rasau Jaya Kabupaten Kubu Raya. E-Jurnal Equilibrium Manajemen, 2(1), 18-22.

Sugiyono. (2016). Statistik Untuk Penelitian. Bandung: Alfabeta.

Sukirno, S. (2016). Mikroekonomi teori pengantar. Jakarta: Rajagrafindo Persada.

Suratiyah, K. (2015). IImu Usahatani. Jakarta: Penebar Swadaya.

Syuwaib. (2018). Analisis Pendapatan Usahatani Bawang Merah (Allium ascalonicum L) di Kampung Maluang Kecamatan Gunung Tabur, Skripsi. STIPER Berau, Teluk Bayur.

Wijayanti, I. K. E. (2001). Prospek Pengembangan Agribisnis Buah-buahan dan Sayuran di Indonesia. Agros, 2(2), 96-105. 